\title{
Cardioprotective Effects of Erythropoietin in Rats Subjected to Ischemia-Reperfusion Injury: Assessment of Infarct Size with ${ }^{99 m}$ Tc-Annexin V
}

\author{
Tomoki Doue ${ }^{1,2}$, Katsuichi Ohtsuki ${ }^{1,2}$, Kazuma Ogawa $^{3}$, Masashi Ueda ${ }^{4}$, Akihiro Azuma ${ }^{1}$, Hideo Saji ${ }^{5}$, Harry W. Strauss ${ }^{6}$, \\ and Hiroaki Matsubara ${ }^{1}$ \\ ${ }^{1}$ Department of Cardiology and Nephrology, Kyoto Prefectural University of Medicine, Kyoto, Japan; ${ }^{2}$ Department of Medicine, Meiji \\ University of Integrative Medicine, Nantan, Japan; ${ }^{3}$ Division of Tracer Kinetics, Advanced Science Research Center, Kanazawa \\ University, Kanazawa, Japan; ${ }^{4}$ Radioisotopes Research Laboratory, Kyoto University Hospital Faculty of Medicine, Kyoto University, \\ Kyoto, Japan; ${ }^{5}$ Department of Patho-Functional Bioanalysis, Graduate School of Pharmaceutical Sciences, Kyoto University, Kyoto, \\ Japan; and ${ }^{6}$ Division of Nuclear Medicine, Department of Radiology, Memorial Sloan-Kettering Hospital, New York, New York
}

\begin{abstract}
Administration of erythropoietin (EPO) during or immediately after myocardial ischemia can reduce subsequent myocardial apoptosis, a key phenomenon in myocardial ischemia-reperfusion injury. In this study, we assessed the effect of EPO on ${ }^{99 m T c-}$ annexin $\mathrm{V}$ myocardial uptake and whether the accumulation of 99m Tc-annexin $\mathrm{V}$ can predict cardiac remodeling and functional deterioration. Methods: Eighteen rats with left coronary artery (LCA) occlusion were randomized to receive either an intravenous injection of EPO (EPO group) or saline (nontherapy [nT] group) immediately after release of the occlusion. After $20 \mathrm{~min}$ of LCA occlusion and 30 min of reperfusion, the rats were injected with ${ }^{99 m}$ Tc-annexin V. One hour after ${ }^{99 m}$ Tc-annexin V injection, the LCA was reoccluded and ${ }^{201} \mathrm{TI}$ was injected intravenously, and the rats were sacrificed 1 min later. The heart was removed and sectioned, and dual-tracer autoradiography was performed to evaluate the distribution of the area at risk (defined on the thallium autoradiograph) and the area of apoptosis (defined on the annexin autoradiograph). Adjacent histologic specimens had deoxyuridine triphosphate nick-end labeling (TUNEL) staining to confirm the presence of apoptosis and were compared with autoradiography. Another 16 rats were randomized to EPO and $\mathrm{nT}$ groups and underwent echocardiography immediately after release of the LCA occlusion and at 2 and 4 wk after surgery. Results: The areas of ${ }^{99 m} \mathrm{Tc}$-annexin $\mathrm{V}$ accumulation in the EPO group were smaller than those in the $\mathrm{nT}$ group, though the ${ }^{201} \mathrm{TI}$ defect areas of these 2 groups were comparable (area ratio, $0.318 \pm 0.038$ vs. $0.843 \pm 0.051, P<0.001$, for annexin and $24.8 \pm 2.1$ vs. $25.9 \pm 2.6 \mathrm{~mm}^{2}, P=\mathrm{NS}$, for thallium). $99 \mathrm{~m} T c-a n n e x i n \mathrm{~V}$ accumulation correlated with the density of TUNEL-positive cells $(r=0.886, P<0.001)$. In the nT group, left ventricular end-diastolic dimension (Dd) increased from baseline at 2 wk by $34.7 \% \pm 3.8 \%$ and remained stable at $34.9 \% \pm 5.0 \%$ at $4 \mathrm{wk}$ after coronary occlusion. In the EPO group, Dd increased by $8.5 \% \pm 2.1 \%(P<0.01$ vs. nT at 2 wk) and $13.2 \% \pm 2.8 \%(P<0.01$ vs. nT at $4 \mathrm{wk})$. In the nT group,
\end{abstract}

Received Feb. 17, 2008; revision accepted Jul. 1, 2008.

For correspondence or reprints contact: Tomoki Doue, Department of Medicine, Meiji University of Integrative Medicine, Hiyoshi-cho Nantan, Kyoto, 629-0392, Japan.

E-mail: doue@meiji-u.ac.jp

COPYRIGHT $\odot 2008$ by the Society of Nuclear Medicine, Inc. the left ventricular percentage of fractional shortening decreased by $42.2 \% \pm 3.4 \%$ and $52.9 \% \pm 3.4 \%$ at 2 and $4 \mathrm{wk}$, respectively, whereas in the EPO group it decreased $9.0 \% \pm$ $1.9 \%$ at 2 wk $(P<0.01$ vs. $\mathrm{nT}$ at $2 \mathrm{wk})$ and $11.1 \% \pm 6.7 \%$ at 4 wk $(P<0.01$ vs. nT at 4 wk). Conclusion: This study demonstrated that a single treatment with EPO immediately after release of coronary ligation suppressed cardiac remodeling and functional deterioration. ${ }^{99 m T c-a n n e x i n ~} \mathrm{~V}$ autoradiographs and TUNEL staining confirm that this change is due to a decrease in the extent of myocardial apoptosis in the ischemic/ reperfused region.

Key Words: 99mTc-annexin V; erythropoietin; reperfusion; apoptosis

J Nucl Med 2008; 49:1694-1700

DOI: 10.2967/jnumed.107.050260

$\mathbf{R}$ estoration of oxygen to ischemic myocardium induces apoptosis in the ischemic myocytes (1-4). In severe, prolonged ischemia, apoptosis occurs before necrosis during the later stages of ischemic injury $(5,6)$. Elimination or reduction of apoptosis would reduce the infarction and the likelihood of cardiac remodeling and of decreased left ventricular (LV) function in the infarction region and, overall, could improve prognosis.

Although erythropoietin (EPO) was developed as a hematopoietic growth factor, stimulating the production and release of red blood cells, EPO has recently been shown to protect ischemic neural and myocardial tissue (7-9). The hematologic and neuro/cardioprotective roles of EPO are caused by the interaction of EPO with 2 different receptors. The classic EPO receptor is responsible for the red blood cell response, whereas the interaction with the $\beta$ common-receptor is responsible for the tissue protective effects $(10)$. In a rat study, EPO administration dramatically reduced infarct size, resulting in improvement of long-term cardiac contractility (11). A single dose of EPO administered immediately after release of coronary artery ligation reduced LV remodeling 
and dysfunction in animals undergoing experimental myocardial infarction, though the dose of EPO was far above that usually used to treat anemia (12). Additional studies explored various doses and intervals between ischemic injury and EPO administration to preserve cardiac function after ischemiareperfusion injury (12-14). The antiapoptotic effect of EPO has been suggested as the mechanism for myocardial preservation.

Under normal circumstances, phosphatidylserine, a constituent of membrane phospholipids, is actively restricted to the inner leaflet of the plasma membrane by the action of 2 enzymes, translocase and floppase. Early in the course of apoptosis, these enzymes are inactivated. As translocase and floppase are inactivated, scramblase, an enzyme that equilibrates the membrane lipids on the inner and outer leaflet of the cell membrane, is activated. This combination of enzyme inactivation and activation results in the rapid appearance of phosphatidylserine on the outer leaflet of the cell membrane (15).

Annexin V, a physiologic protein with a molecular weight of about $36 \mathrm{kD}$, binds with nanomolar affinity to membranebound phosphatidylserine $(16,17)$. Both in vitro and in vivo methods have been developed that use this characteristic of annexin $\mathrm{V}$ binding to identify cells in the early stages of apoptosis (18-20). For example, Peker et al. have used ${ }^{99 \mathrm{~m}} \mathrm{Tc}-$ labeled annexin $\mathrm{V}$ to detect apoptosis as a result of ischemia-reperfusion injury in vivo (21). Other investigators have used radiolabeled annexin $\mathrm{V}$ to identify apoptosis in acute cardiac allograft rejection, subacute myocarditis, and acute doxorubicin cardiotoxicity (20-22).

This study was performed to determine the effect of a single intravenous dose of EPO on apoptotic activity and ventricular function in animals subjected to ischemia-reperfusion.

\section{MATERIALS AND METHODS}

\section{Materials}

Mutant annexin V (annexin V-117, a recombinant human annexin engineered to include a binding site for technetium, generously provided by John Tait, University of Washington) was produced by expression in Escherichia coli as previously described (23). This material preserves phosphatidylserine-binding activity equivalent to that of native annexin V. Labeling efficiency was consistently above $92 \%$, providing a specific activity of approximately $7.4 \mathrm{MBq}$ per microgram of protein using a previously described radiolabeling protocol (23). Under these conditions, annexin V labeling was stable for at least $4 \mathrm{~h}$.

Recombinant human EPO was kindly provided by Chugai Pharmaceutical Co., Ltd.

\section{Animal Model of Ischemia and Reperfusion Injury}

Eighteen Male Wister rats (10 wk old; body weight, $305 \pm 12.4 \mathrm{~g}$ ) were anesthetized with intraperitoneally administered pentobarbital (20 $\mathrm{mg} / \mathrm{kg}$ ) and intubated, and anesthesia was maintained with inhalation of $2 \%$ isoflurane in $1.0 \mathrm{~L}$ of oxygen/min during volumecontrolled ventilation. The heart was exposed through a left thoracotomy; a pledgeted 5-0 silk suture on a small, curved needle was passed through the myocardium beneath the proximal portion of the left coronary artery (LCA); and both ends of the suture were passed through a small vinyl tube to make a snare. The suture material was pulled tightly against the vinyl tube and secured by a keeper on the tube to occlude the LCA. Animals were randomized to receive either a single intravenous injection of EPO (200 units $/ \mathrm{kg}$ in $0.3 \mathrm{~mL}$ of saline) or an equivalent volume of saline immediately after release of LCA occlusion (EPO group and nontherapy [nT] group, respectively, $n=9$ in each). Myocardial ischemia was confirmed by ST-segment elevation on electrocardiography, regional cyanosis of the myocardial surface, and decreased regional wall motion. After a 20-min occlusion of the LCA, reperfusion was obtained by removal of the keeper and release of the snare and was confirmed by the change from cyanotic to pink in the myocardial risk area. During reperfusion, the snare was left loose on the surface of the heart for reocclusion. Approximately $55.5 \mathrm{MBq}$ of ${ }^{99 \mathrm{~m}} \mathrm{Tc}$-annexin $\mathrm{V}$ were injected via a tail vein at $30 \mathrm{~min}$ after reperfusion. One hour after ${ }^{99 \mathrm{~m}} \mathrm{Tc}$-annexin $\mathrm{V}$ injection, the snare occluder was again pulled tightly and $0.185 \mathrm{MBq}$ of ${ }^{201} \mathrm{Tl}$ was injected via a tail vein to delineate the area at risk. One minute later, the rat was euthanized by a bolus injection of $4 \mathrm{~mL}$ of $0.5 \mathrm{M} \mathrm{KCl}$. The heart was excised, rapidly rinsed in saline, embedded in methylcellulose, and frozen in iced $n$-hexane. Serial short-axis heart sections (20- and 8- $\mu \mathrm{m}$ shortaxis sections adjacent to each other) were obtained using a cryostat for autoradiography and histologic analysis, respectively. This study was approved by the institutional Animal Care Committee at Kyoto Prefectural University of Medicine.

\section{Dual-Tracer Autoradiography}

Dual-tracer autoradiography of the LV short-axis slices was performed using a bio-imaging analyzer system (BAS5000; Fuji Film). The apoptotic area was determined from the ${ }^{99 \mathrm{~m}} \mathrm{Tc}$-annexin $\mathrm{V}$ uptake area, and the area at risk was determined from the ${ }^{201} \mathrm{Tl}$ defect area. The first autoradiographic exposure was performed for $30 \mathrm{~min}$ to visualize ${ }^{99 \mathrm{~m}} \mathrm{Tc}$-annexin V. Approximately $72 \mathrm{~h}$ later (12 half-lives of ${ }^{99 \mathrm{~m}} \mathrm{Tc}$ ), the second exposure of the same heart sections was performed for $36 \mathrm{~h}$ to delineate the area at risk, expressed as ${ }^{201} \mathrm{Tl}$ defect area.

\section{Data Analysis of Autoradiography}

The extent and the density of the 2 radionuclides were quantitatively analyzed using the bio-imaging analyzer system. After exposure, the bioimaging plate was placed in a reader to determine the photostimulated luminescence (PSL) in each pixel $(25 \times 25 \mu \mathrm{m})$. These data were recorded for each animal and each nuclide. The accumulation of ${ }^{99 \mathrm{~m}} \mathrm{Tc}$-annexin $\mathrm{V}$ was assessed in 4 midventricular short-axis frozen sections. The region of decreased thallium activity seen on the autoradiograph was outlined, and the region of interest was transferred to the ${ }^{99 \mathrm{~m}} \mathrm{Tc}$-annexin $\mathrm{V}$ autoradiograph to evaluate ${ }^{99 \mathrm{~m}} \mathrm{Tc}$-annexin V uptake. Four background ROIs were set adjacent to the left ventricle in each autoradiograph, and the mean PSL per unit area $\left(1 \mathrm{~mm}^{2}\right)$ of the 4 background ROIs was defined as background tracer uptake. The uptake values of each ROI were calculated as the background-corrected PSL per unit area $\left(1 \mathrm{~mm}^{2}\right)$. The area ratio and the density ratio were defined as the indicator to evaluate the extent and intensity, respectively, of ${ }^{99 m} \mathrm{Tc}$-annexin $\mathrm{V}$ uptake. The area ratio calculated by dividing ${ }^{99 \mathrm{~m}} \mathrm{Tc}$-annexin $\mathrm{V}$ uptake area by ${ }^{201} \mathrm{Tl}$ defect area indicates the extent of the apoptotic area in the area at risk. The density ratio of ${ }^{99 \mathrm{~m}} \mathrm{Tc}$-annexin $\mathrm{V}$ was calculated by dividing the uptake values of the ${ }^{99 \mathrm{~m} T c-a n n e x i n ~} \mathrm{~V}$ uptake area by that of the normally perfused area. All parameters were expressed as an average value obtained from the analysis of 4 midventricular short-axis slices in each rat. 


\section{Histopathologic Examinations}

Four sets of short-axis frozen sections adjacent to the slices for autoradiography were stained with terminal deoxynucleotidyl transferase-mediated deoxyuridine triphosphate nick-end labeling (TUNEL) using a commercially available kit (in situ cell death detection kit, fluorescein isothiocyanate labeling; Roche Applied Science) according to the manufacturer's protocol. As a positive control of TUNEL staining, we used rat intestine. Rhodaminelabeled $\alpha$-sarcomeric actinin (DAKO) was simultaneously used for the detection of muscular structures. Digital photographs were taken under confocal microscopy at $200 \times$ magnification. TUNEL-positive cardiomyocytes were counted in 20 randomly chosen fields within the area at risk for each section. The mean density ratio of ${ }^{99 \mathrm{~m}} \mathrm{Tc}-$ annexin $\mathrm{V}$ was compared with the mean number of TUNEL-positive myocytes in the corresponding area of each rat. Another 2 sets of short-axis frozen sections adjacent to the slices for autoradiography were stained with hematoxylin and eosin and examined histopathologically by light microscopy.

\section{Echocardiography}

Sixteen 10-wk-old Wistar rats (body weight, $308 \pm 15.6 \mathrm{~g}$ ) were anesthetized (sodium pentobarbital, $30 \mathrm{mg} / \mathrm{kg}$ intraperitoneally) for a baseline ventricular function measurement by echocardiography (Sonos 5500 equipped with a $15-\mathrm{MHz}$ phased-array transducer; Philips Electronics N.V.). The anesthetized rats were subjected to 20 min of myocardial ischemia and $30 \mathrm{~min}$ of reperfusion. Half the animals received a single intravenous injection of EPO (200 units $/ \mathrm{kg}$ in $0.3 \mathrm{~mL}$ of saline) immediately after LCA occlusion (EPO group). The other rats received an equivalent volume of saline at the same time point (nT group). Echocardiography was performed immediately after release of the LCA occlusion and repeated at 2 and $4 \mathrm{wk}$ after surgery. A parasternal long-axis view was recorded, ensuring that the mitral and aortic valves and the apex were visualized. A short-axis view was recorded at the level of the mid papillary muscles. Both 2-dimensional and motion-mode views were recorded at the same level. LV end-diastolic dimension (Dd) and endsystolic dimension (Ds) were measured from motion mode in both short- and long-axis views. The LV percentage of fractional shortening $(\% \mathrm{FS})$ in the long-axis view was calculated as $\% \mathrm{FS}=(\mathrm{Dd}-$ $\mathrm{Ds}) / \mathrm{Dd} \times 100$. All measurements were taken and averaged over 5 consecutive cardiac cycles by 1 observer who was unaware of the treatment with EPO. The reproducibility of measurements was assessed at baseline by 2 sets of measurements in 10 randomly selected rats. The repeated-measures variability did not exceed $\pm 5 \%$. Blood $(0.5 \mathrm{~mL})$ was collected from the jugular vein under pentobarbital anesthesia just before and after operation and at 4, 10, and $28 \mathrm{~d}$ after operation to determine the hematocrit level (measured in triplicate).

\section{Statistical Analysis}

Results were expressed as mean \pm SD. Statistical analyses were performed using a Windows computer with StatView software (version 5.0; SAS Institute Inc.). Comparisons between the 2 groups were made using an unpaired $t$ test. The time course of the changes was compared by repeated-measures ANOVA with the Scheffé post hoc test. The relationship of ${ }^{99 \mathrm{~m}} \mathrm{Tc}$-annexin V uptake in the area at risk was correlated with the number of TUNEL-positive cells by linear regression. A value of $P$ less than 0.05 was considered statistically significant.

\section{RESULTS}

\section{Autoradiographic Detection of Early Apoptotic Cells}

Representative images of dual autoradiography are shown in Figure 1. In the nT group, ${ }^{99 \mathrm{~m}} \mathrm{Tc}$-annexin $\mathrm{V}$ accumulated strongly at the central zone of the myocardial area at risk, predominantly in the mid layer of myocardium. Compared with the nT group, the accumulation of ${ }^{99 \mathrm{~m}} \mathrm{Tc}$-annexin $\mathrm{V}$ was reduced in the EPO group. The areas of ${ }^{99 \mathrm{~m}} \mathrm{Tc}$-annexin $\mathrm{V}$ accumulation were smaller in the EPO group than in the $\mathrm{nT}$ group. Quantitative analyses demonstrated that the area ratio and density ratio of the EPO group were significantly smaller than those of the nT group (area ratio, $0.318 \pm 0.038$ vs. $0.843 \pm 0.051, P<0.001 ;$ density ratio, $22.2 \pm 4.2$ vs. $108.3 \pm$ 14.0, $P<0.0001$ ) (Fig. 2). The ${ }^{201} \mathrm{Tl}$ transmural defect areas of these 2 groups did not significantly differ in size $(24.8 \pm$ 2.1 vs. $\left.25.9 \pm 2.6 \mathrm{~mm}^{2}, P=0.56\right)$.

\section{Comparison of Histologic Findings with ${ }^{99 m}$ Tc-Annexin V Autoradiography}

Figure 3 showed the representative tissue sections of TUNEL staining in each group. The myocardium in both groups showed no inflammatory cells, no necrotic cells, and no myocardial degeneration on the light microscopic examination of the hematoxylin- and eosin-stained slices. TUNEL-positive cells were scattered at the mid layer of the myocardial area at risk in the nT group. In contrast, TUNEL-positive cells were localized to a small area in the EPO group. In both groups, the distribution of TUNEL-positive cells agreed closely with
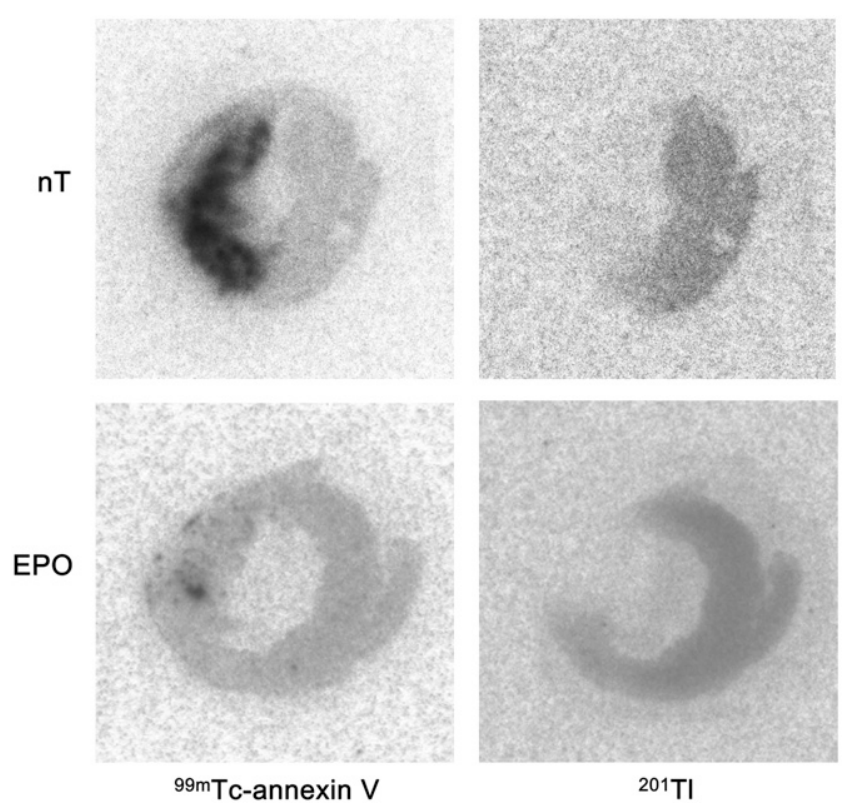

FIGURE 1. Autoradiography of $99 \mathrm{~m} T \mathrm{~T}$-annexin $\mathrm{V}$ and ${ }^{201} \mathrm{TI}$. Midventricular slices are shown from representative animals from each group. ${ }^{99 m}$ Tc-annexin $V$ uptake area indicates myocardial apoptotic area, whereas ${ }^{201} \mathrm{TI}$ defect area demonstrates area at risk. In $\mathrm{nT}$ group, ${ }^{99 \mathrm{~m} T c-a n n e x i n ~} \mathrm{~V}$ highly accumulated at central zone of myocardial area at risk. Compared with nT group, accumulation of 99mTc-annexin V was reduced in EPO group with regard to both size and density. 


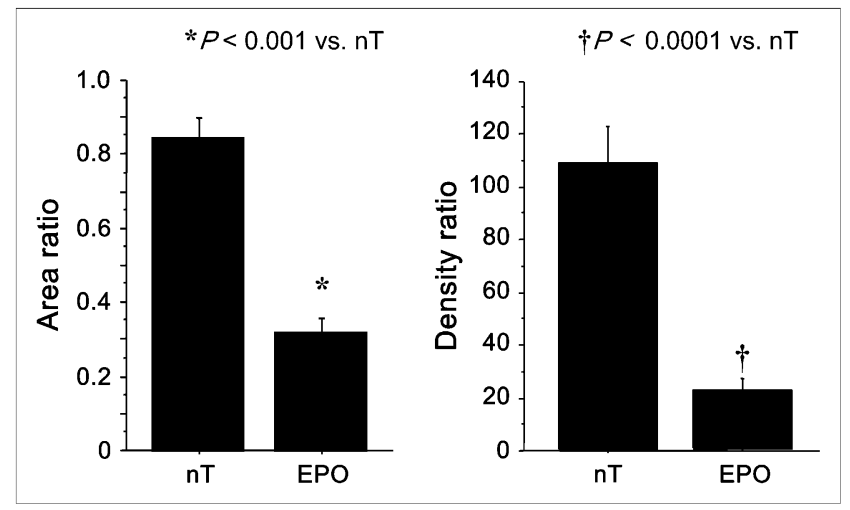

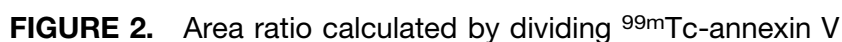
uptake area by ${ }^{201} \mathrm{TI}$ defect area would indicate extent of apoptotic area in area at risk. Density ratio calculated by dividing uptake value of $99 \mathrm{mTc}$-annexin V uptake area by that of normally perfused area would reflect intensity of apoptosis in apoptotic area. Area ratio and density ratio of EPO group were significantly smaller than those of nT group (area ratio: $0.318 \pm$ 0.038 vs. $0.843 \pm 0.051, P<0.001$; density ratio: $22.2 \pm 4.2$ vs $108.3 \pm 14.0, P<0.0001)$.

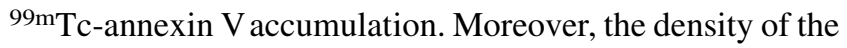
TUNEL-positive cells (the number of TUNEL-positive cells per high-power field [HPF]) in the EPO group was significantly smaller than that in the nT group $(34.1 \pm 11.7 / \mathrm{HPF}$ vs. $136.8 \pm 25.9 / \mathrm{HPF}, P<0.01$ ) (Fig. 4).

Figure 5 compares the density of TUNEL-positive cells in the representative myocardial apoptotic area (the number of TUNEL-positive cells per HPF) of each rat with the density of ${ }^{99 \mathrm{~m}} \mathrm{Tc}$-annexin $\mathrm{V}$ accumulation $\left(\mathrm{PSL} / \mathrm{m}^{2}\right)$ in the corresponding area. The density of ${ }^{99 \mathrm{~m}} \mathrm{Tc}$-annexin Vaccumulation correlated well with the density of TUNEL-positive cells $(r=0.886, P<0.01)$.

\section{The Influence of EPO on Hematocrit}

The average changes in hematocrit in rats treated with EPO (200 units $/ \mathrm{kg}$ in $0.3 \mathrm{~mL}$ of saline) did not differ from those receiving an equivalent volume of saline just before and after operation and at 4, 10, and $28 \mathrm{~d}$ after operation (Table 1 ).

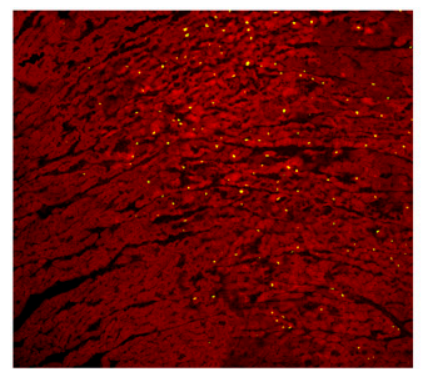

nT

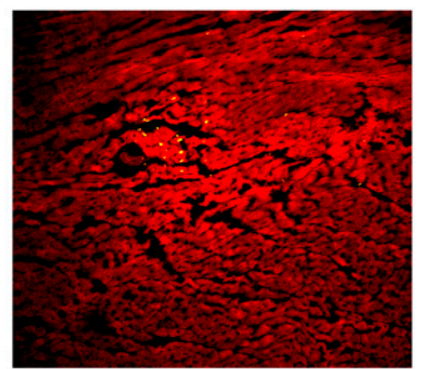

EPO
FIGURE 3. Representative tissue section of TUNEL staining is shown in each group. TUNEL-positive cells were scattered at mid layer of myocardial area at risk in nT group. In contrast, TUNEL-positive cells were localized to very small area in EPO group.

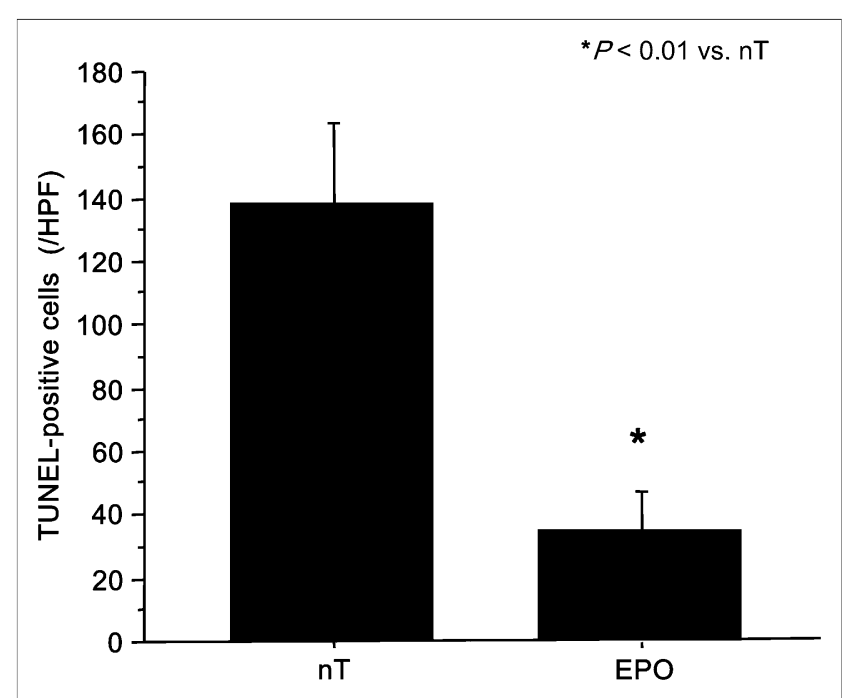

FIGURE 4. Tissue sections of TUNEL staining were observed under confocal microscopy at 200x magnification. Density of TUNEL-positive cells (number of TUNEL-positive cells per HPF) in EPO group was significantly smaller than that of $\mathrm{nT}$ group $(34.1 \pm 11.7 / \mathrm{HPF}$ vs. $136.8 \pm 25.9 / \mathrm{HPF}, P<0.01)$.

\section{Echocardiography}

Baseline (presurgery) measurements of LV cavity size (Dd) and LV systolic function (\%FS) were similar in the groups assigned to EPO and nT. After coronary ligation/ release, the depression in ejection fraction $(36.1 \pm 3.9$ vs. $36.8 \pm 3.1, P=0.91$ ) was similar in the 2 groups (Table 2 ).

Figure 6 illustrates the average changes in Dd and \%FS at 2 and 4 wk after ischemia-reperfusion injury. In the nT group, Dd increased to a greater extent from 0 to $2 \mathrm{wk}$ than from 2 to $4 \mathrm{wk}$. The percentage change in Dd at 2 and $4 \mathrm{wk}$ after the surgical procedure, compared with baseline data immediately after ischemia-reperfusion injury, was $34.7 \% \pm$

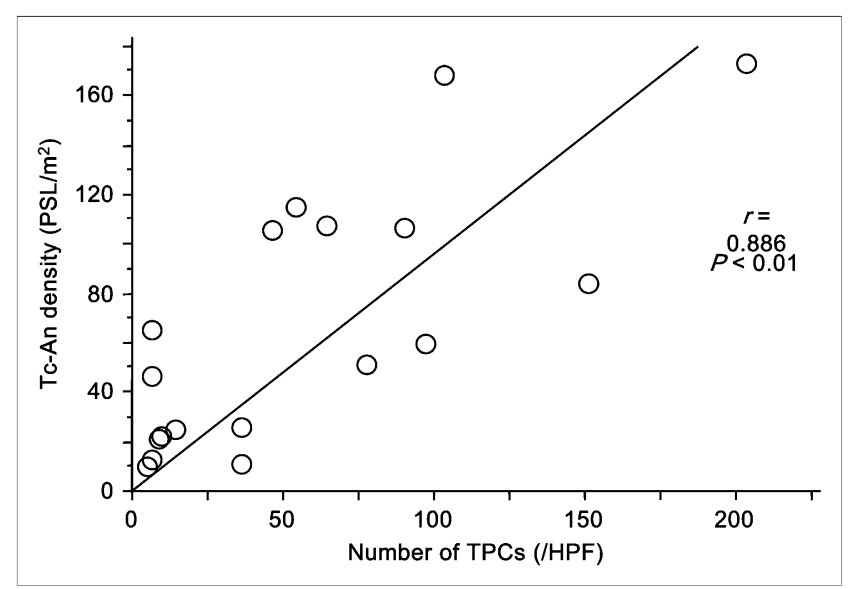

FIGURE 5. Comparison of density of TUNEL-positive cells in representative myocardial apoptotic area (number of TUNELpositive cells per HPF) of each rat with density of ${ }^{99 m}$ Tc-annexin $\mathrm{V}$ accumulation (PSL/ $\mathrm{m}^{2}$ ) in corresponding area. Density of 99mTc-annexin $\mathrm{V}$ accumulation correlated well with density of TUNEL-positive cells $(r=0.886, P<0.01)$. 
TABLE 1

Serial Measurements of Hematocrit After a Single Administration of EPO or Saline

\begin{tabular}{lccccc}
\hline Administered substance & Just before operation & Just after operation & Day 4 & Day 10 & Day 28 \\
\hline Saline (6) & $40.9 \pm 0.4$ & $41.9 \pm 0.4$ & $42.6 \pm 0.7$ & $41.6 \pm 0.4$ & $40.9 \pm 0.6$ \\
EPO (6) & $40.1 \pm 0.3$ & $41.1 \pm 0.4$ & $42.3 \pm 0.5$ & $42.4 \pm 0.5$ & $42.6 \pm 0.8$
\end{tabular}

Data are mean percentage \pm SD.

$3.8 \%$ and $34.9 \% \pm 5.0 \%$, respectively. On the other hand, in the EPO group, the percentage change in Dd at 2 and $4 \mathrm{wk}$ after ischemia-reperfusion injury was just $8.5 \% \pm 2.1 \%$ $(P<0.01$ vs. nT at $2 \mathrm{wk})$ and $13.2 \% \pm 2.8 \%(P<0.01$ vs. nT at $4 \mathrm{wk})$, respectively.

A significant difference was observed in $\% \mathrm{FS}$ between the $\mathrm{EPO}$ and $\mathrm{nT}$ groups over the 4-wk follow-up. Compared with the baseline data immediately after ischemia-reperfusion injury, $\% \mathrm{FS}$ in the $\mathrm{nT}$ group declined by $42.2 \% \pm 3.4 \%$ and $52.9 \% \pm 3.4 \%$ at 2 and $4 \mathrm{wk}$. The LV performance of the nT group declined more steeply from 0 to 2 wk than from 2 to 4 wk. The $\%$ FS in the EPO group decreased slightly at $2 \mathrm{wk}$ $(-9.0 \% \pm 1.9 \%, P<0.01$, vs. nTat $2 \mathrm{wk})$ and $4 \mathrm{wk}(-11.1 \% \pm$ $6.7 \%, P<0.01$, vs. nT at $4 \mathrm{wk})$.

These data suggest that the marked enlargement of the LV cavity and the steep decline of LV contractile function occurring in the nT group in the $2 \mathrm{wk}$ after occlusion/release was suppressed by a single injection of EPO.

\section{DISCUSSION}

In this study, the extent of apoptosis after ischemiareperfusion injury was markedly reduced after a single intravenous dose of EPO. This reduction of apoptosis was seen in histologic TUNEL staining of the myocardium in the area at risk and in autoradiographic studies with ${ }^{99 \mathrm{~m}} \mathrm{Tc}$-annexin $\mathrm{V}$ within $1 \mathrm{~h}$ of EPO administration. Moreover, echocardiography demonstrated that a single systemic administration of EPO immediately after coronary ligation minimized LV remodeling and preserved contractile function at 2 and $4 \mathrm{wk}$ after surgery.

${ }^{99 \mathrm{~m}} \mathrm{Tc}-$ annexin $\mathrm{V}$ has been reported to be highly sensitive in detecting apoptosis immediately after ischemia-reperfusion myocardial injury $(24,25) .{ }^{99 \mathrm{~m}} \mathrm{Tc}$-annexin $\mathrm{V}$ has been used to

TABLE 2

Baseline Echocardiographic Parameters in EPO-Treated and Control Rats

\begin{tabular}{clcc}
\hline Index & Group & Before operation & After operation \\
\hline LVDd $(\mathrm{mm})$ & $\mathrm{nT}$ & $6.2 \pm 0.1$ & $6.5 \pm 0.2$ \\
& EPO & $6.3 \pm 0.1$ & $6.6 \pm 0.2$ \\
$\% \mathrm{FS}$ & $\mathrm{nT}$ & $61.3 \pm 1.3$ & $36.8 \pm 3.1$ \\
& EPO & $62.2 \pm 0.9$ & $36.1 \pm 3.9$
\end{tabular}

Data are mean $\pm S D$. image injured myocardium after acute $\mathrm{MI}$ in patients undergoing acute coronary angioplasty (26). In 6 of 7 patients, increased uptake of ${ }^{99 \mathrm{~m}} \mathrm{Tc}$-annexin $\mathrm{V}$ was seen in the infarct area of the heart on early and late SPECT images, suggesting that apoptosis occurs in that area. Taki et al. reported similar findings with ${ }^{99 \mathrm{~m}} \mathrm{Tc}$-annexin $\mathrm{V}$ localization in the area at risk early after ischemia-reperfusion injury (14). The concentration of ${ }^{99 \mathrm{~m}} \mathrm{Tc}$-annexin $\mathrm{V}$ in the area at risk was concordant with the distribution of TUNEL-positive cells. In their study, ${ }^{99 \mathrm{~m} T c-a n n e x i n} \mathrm{~V}$ accumulation was most prominent at $30-90$ min after reperfusion and then gradually declined, whereas the number of TUNEL-positive cells peaked at $6 \mathrm{~h}$ to $1 \mathrm{~d}$ after reperfusion. In our study, ${ }^{99 \mathrm{~m}} \mathrm{Tc}$-annexin $\mathrm{V}$ accumulation clearly delineated the area of the apoptotic myocardium in the 20-min occlusion/30-min reperfusion model, consistent with the results of previous studies $(14,24,25$,). The previous investigation reported that, with TUNEL staining, EPO can limit the size of LV infarction (12). In this study, EPO therapy caused a 2.7 -fold reduction of ${ }^{99 \mathrm{~m}} \mathrm{Tc}$-annexin Vaccumulation in the ischemic risk area.

Previous studies reported that a single administration of EPO increased the number of circulating reticulocytes by $3-4 \mathrm{~d}$ (reaching a maximum by days $8-11)(27,28)$. In the present study, the hematocrit in the rats treated with EPO did not differ from that in rats receiving saline just after operation and at 4, 10, and $28 \mathrm{~d}$ after operation. Therefore, the response

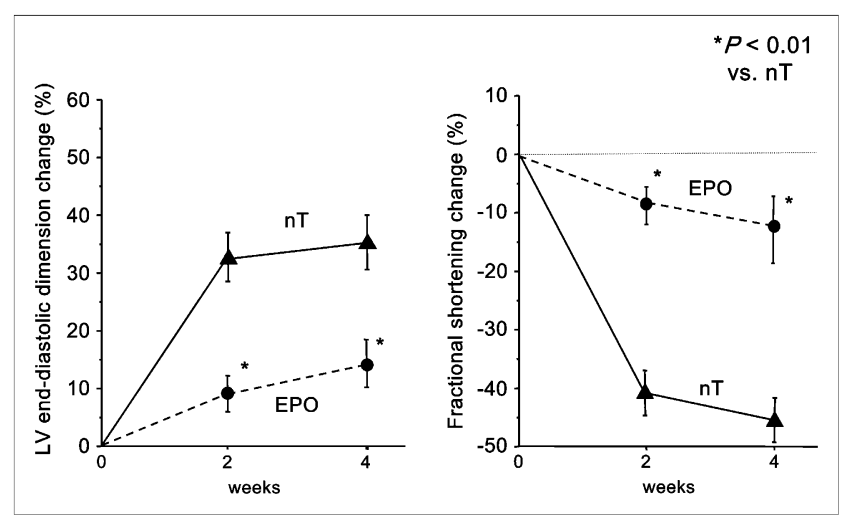

FIGURE 6. Changes in echocardiographic indices of LV size (Dd) and function (fractional shortening) during $4 \mathrm{wk}$ after ischemia-reperfusion injury in EPO-treated and untreated rats. All indices are expressed as percentage change from baseline values (Table 2). *Significant difference $(P<0.01)$ between $\mathrm{nT}$ and EPO groups in percentage change in LV Dd and fractional shortening at weeks 2 and 4 . 
seen in the current experiment is unlikely related to an increase in the oxygen-carrying capacity of the blood.

The cardio- and neuroprotective properties are likely due to the interaction of EPO with the common $\beta$-receptor. This receptor requires a higher concentration of EPO and has the effect of reducing apoptosis. Previous studies in a rabbit model demonstrated that a single dose of EPO (5,000 units/ $\mathrm{kg}$ ) reduced infarct size from $35 \%$ to $13.8 \%$, in keeping with the results in the present study (3). This acute effect persists over the subsequent 4-wk interval of observation. Previous observations have demonstrated a favorable influence of the antiapoptotic effect of EPO on long-term LV chamber size and function after myocardial ischemia $(12,13)$. Moon et al. showed that a single dose of EPO at the onset of myocardial infarction reduced infarct size and reduced LV remodeling and dysfunction measured by echocardiography during the subsequent 8-wk period (12). Our results confirm that a single intravenous injection of EPO immediately after coronary occlusion suppressed LV remodeling and contractile deterioration at $4 \mathrm{wk}$ after surgery. The results of ${ }^{99 \mathrm{~m}} \mathrm{Tc}$-annexin $\mathrm{V}$ autoradiography and TUNEL staining suggest that the beneficial effect of EPO is due to a remarkable suppression of apoptosis in the area at risk in this rat ischemia-reperfusion injury model. The mechanism of apoptosis reduction may be due to a phosphatidylinositol-3 kinase/Akt dependent pathway, as demonstrated in vivo in dog hearts (29).

Although prolonged administration of EPO is associated with adverse effects related to hematocrit elevation, such as hypertension and thromboembolic complications $(30,31)$, a single administration of EPO, even at the higher doses used in this study, had a beneficial effect on the preservation of cardiac function after ischemia-reperfusion injury.

This study had 2 limitations. The first was the inability to assess the other effects of EPO on LV remodeling and function after myocardial infarction, though more recent studies reported that EPO possesses proangiogenic properties promoting neovascularization related to infarct size reduction after myocardial infarction (32). The second limitation was that we studied the feasibility of ${ }^{99 \mathrm{~m}} \mathrm{Tc}$-annexin $\mathrm{V}$ to assess the antiapoptotic treatment of EPO at only 1 time point, 30 min after the beginning of reperfusion. Further examination is needed to know the optimal timing for EPO injection as well as the optimum time for ${ }^{99 \mathrm{~m}} \mathrm{Tc}$-annexin V injection and imaging to assess the cardioprotective effect of EPO.

\section{CONCLUSION}

The present study demonstrated that ${ }^{99 \mathrm{~m}} \mathrm{Tc}$-annexin $\mathrm{V}$ is useful to evaluate myocardial apoptosis associated with ischemia-reperfusion injury. The ratio of the perfusion area at risk to annexin $\mathrm{V}$ lesion size is a useful indicator of myocardium salvaged by acute administration of EPO. The echocardiographic study showed that a single treatment with EPO immediately after coronary ligation suppressed cardiac remodeling and functional deterioration for at least $4 \mathrm{wk}$ after the acute insult. These studies suggest that a single dose of
EPO may be useful to prevent long-term cardiac remodeling and dysfunction after ischemia-reperfusion injury.

\section{ACKNOWLEDGMENT}

We thank Nihon Medi-Physics Co., Ltd., for its constant support, inclusive of radioisotope supply. This study was supported in part by grant-in-aid B-18790919 for young scientists from the Ministry of Education, Science, Sports, and Culture, Japan.

\section{REFERENCES}

1. Fliss H, Gautinger D. Apoptosis in ischemic and reperfused rat myocardium. Circ Res. 1996;79:949-956.

2. Gottlieb RA, Burleson KO, Kloner RA, et al. Reperfusion injury induces apoptosis in rabbit cardiomyocytes. J Clin Invest. 1994;94:1621-1628.

3. Parsa CJ, Matsumoto A, Kim J, et al. A novel protective effect of erythropoietin in the infarcted heart. J Clin Invest. 2003;112:999-1007.

4. Cai Z, Semenza GL. Phosphatidylinositol-3-kinase signaling is required for erythropoietin-mediated acute protection against myocardial ischemia/reperfusion injury. Circulation. 2004;109:2050-2053.

5. Maulik N, Kagan VE, Tyurin VA, et al. Redistribution of phosphatidylethanolamine and phosphatidylserine precedes reperfusion-induced apoptosis. Am J Physiol. 1998;274:H242-H248.

6. Martin SJ, Reutelingsperger $\mathrm{CP}$, McGahon AJ, et al. Early redistribution of plasma membrane phosphatidylserine is a general feature of apoptosis regardless of the initiating stimulus: inhibition by overexpression of Bcl-2 and Abl. $J$ Exp Med. 1995;182:1545-1556.

7. Digicaylioglu M, Bichet S, Marti HH, et al. Localization of specific erythropoietin binding sites in defined areas of the mouse brain. Proc Natl Acad Sci USA. 1995;92:3717-3720.

8. Ehrenreich H, Hasselblatt M, Dembowski C, et al. Erythropoietin therapy for acute stroke is both safe and beneficial. Mol Med. 2002;8:495-505.

9. Sakanaka M, Wen TC, Matsuda S, et al. In vivo evidence that erythropoietin protects neurons from ischemic damage. Proc Natl Acad Sci USA. 1998;95:4635-4640.

10. Brines M, Grasso G, Fiordaliso F, et al. Erythropoietin mediates tissue protection through an erythropoietin and common beta-subunit heteroreceptor. Proc Natl Acad Sci USA. 2004;101:14907-14912.

11. Calvillo L, Latini R, Kajstura J, et al. Recombinant human erythropoietin protects the myocardium from ischemia-reperfusion injury and promotes beneficial remodeling. Proc Natl Acad Sci USA. 2003;100:4802-4806.

12. Moon C, Krawczyk M, Ahn D, et al. Erythropoietin reduces myocardial infarction and left ventricular functional decline after coronary artery ligation in rats. Proc Natl Acad Sci USA. 2003;100:11612-11617.

13. Parsa CJ, Jihee K, Riel RU, et al. Cardioprotective effect of erythropoietin in the reperfused ischemic heart. J Biol Chem. 2004;279:20655-20662.

14. Taki J, Higuchi T, Kawashima A, et al. Detection of cardiomyocyte death in a rat

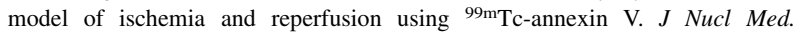
2004;45:1536-1541.

15. Zwaal RFA, Schroit AJ. Pathophysiologic implications of membrane phospholipids asymmetry in blood cells. Blood. 1997;89:1121-1132.

16. Blankenberg FG, Katsikis PD, Tait JF, et al. In vivo detection and imaging of phosphatidylserine expression during programmed cell death. Proc Natl Acad Sci USA. 1998;95:6349-6354.

17. Blankenberg FG, Katsikis PD, Tait JF, et al. Imaging of apoptosis (programmed cell death) with ${ }^{99 m}$ Tc-labeled annexin V. J Nucl Med. 1999;40:184-191.

18. Fadok VA, Laszlo DJ, Noble PW, Weinstein L, Riches DW, Henson PM. Particle digestibility is required for induction of the phosphatidylserine recognition mechanism used by murine macrophages to phagocytose apoptotic cells. J Immunol. 1993;151:4274-4285.

19. Koopman G, Reutelingsperger CP, Kuijten GA, Keehnen RM, Pals ST, van Oers MH. Annexin V for flow cytometric detection of phosphatidylserine expression on B cells undergoing apoptosis. Blood. 1994;84:1415-1420.

20. Narula J, Acio ER, Narula N, et al. Annexin-V imaging for noninvasive detection of cardiac allograft rejection. Nat Med. 2001;7:1347-1352.

21. Peker C, Sarda-Mantel L, Loiseau P, et al. Imaging apoptosis with ${ }^{99 \mathrm{~m} T c-l a b e l e d}$ annexin V in experimental subacute myocarditis. J Nucl Med. 2004;45:10811086. 
22. Bennink RJ, van den Hoff MJ, van Hemert FJ, et al. Annexin V imaging of acute doxorubicin cardiotoxicity (apoptosis) in rats. J Nucl Med. 2004;45:842-848.

23. Tait JF, Brown DS, Gibson DF, et al. Development and characterization of annexin V mutants with endogenous chelation sites for ${ }^{99 \mathrm{~m}} \mathrm{Tc}$. Bioconjug Chem. 2000;11:918-925.

24. Dumont EA, Reutelingsperger CP, Smits JF, et al. Real-time imaging of apoptotic cell-membrane changes at the single-cell level in the beating murine heart. Nat Med. 2001;7:1352-1355.

25. Dumont EA, Hofstra L, van Heerde WL, et al. Cardiomyocyte death induced by myocardial ischemia and reperfusion: measurement with recombinant human annexin-V in a mouse model. Circulation. 2000;102:1564-1568.

26. Hofstra L, Liem IH, Dumont EA, et al. Visualisation of cell death in vivo in patients with acute myocardial infarction. Lancet. 2000;356:209-212.

27. Cheung WK, Goon BL, Guilfoile MC, et al. Pharmacokinetics and pharmacodynamics of recombinant human erythropoietin after single and multiple subcutaneous doses to healthy subjects. Clin Pharmacol Ther. 1998;64:412-423.
28. Eder H, Rosslenbroich B, Failing K. Erythropoietin reduces myocardial infarction and left ventricular functional decline after coronary artery ligation in rats. Blut. 1989;59:184-187.

29. Hirata A, Minamino T, Asanuma H, et al. Erythropoietin just before reperfusion reduces both lethal arrhythmias and infarct size via the phosphatidylinositol-3 kinase-dependent pathway in canine hearts. Cardiovasc Drugs Ther. 2005;19: 33-40.

30. Roger SD, Baker LR, Raine AE. Autonomic dysfunction and the development of hypertension in patients treated with recombinant human erythropoietin ( $\mathrm{r}$ HuEPO). Clin Nephrol. 1993;39:103-110.

31. Wolf RF, Gilmore LS, Friese P, Downs T, Burstein SA, Dale GL. Erythropoietin potentiates thrombus development in a canine arteriovenous shunt model. Thromb Haemost. 1997;77:1020-1024.

32. van der Meer P, Lipsic E, Henning RH, et al. Erythropoietin induces neovascularization and improves cardiac function in rats with heart failure after myocardial infarction. J Am Coll Cardiol. 2005;46:125-133. 